\title{
Información y documentación radiofónica: espacios para un interés común. La experiencia de Radio Nacional de España
}

\author{
Por Laura Prieto
}

Resumen: Se muestra la relación entre la información y la documentación radiofónica desde la perspectiva de la experiencia en Radio Nacional de España. La información radiofónica pivota en torno a tres tipos de materiales: sonoros musicales, sonoros no musicales y escritos. Los distintos perfiles de programas los utilizan en diferente medida, oscilando entre lo más generalista y lo más especializado, en función no de aspectos cuantitativos sino cualitativos desde el punto de vista de los contenidos. El centro de documentación de radio, al servicio de las necesidades profesionales, planifica la cadena documental en función de los materiales y dentro de ella conjuga los requerimientos de respuestas específicas y generales. Todo esto se realiza en el marco de las nuevas tecnologías digitales que afectan tanto a la emisión como al tratamiento y conservación de la información.

Palabras clave: Información radiofónica, Programas de radio, Programas de radio generalistas, Programas de radio informativos, Programas de radio dramáticos, Programas de radio especializados, Documentación radiofónica, Información sonora musical, Información sonora no musical, Información escrita, Análisis documental, Digitalización de soportes, Emisión digital, Radio Nacional de España.

Title: Radiophonic information and documentation: Spaces for common interest. The experience of Spanish National Radio (RNE)

Abstract: Radiophonic information includes three types of materials: music recordings, non-music recordings, and written material. Considering the qualitative rather than quantitative aspects of the extent to which different types of programs use them, the user needs range from the most general to the most specialized content. RNE, the Spanish national radio network, serves as a case study of the relationship between radiophonic information and documentation. The center for radio documentation, at the service of professional needs, plans the document chain based on typology and then addresses the need to respond

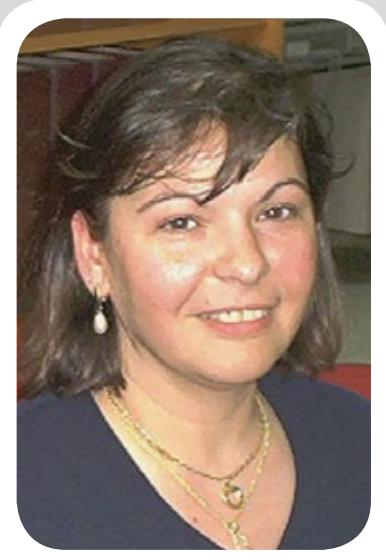

Laura Prieto es experta en documentación radiofónica y documentación musical, áreas en las que centra su actividad investigadora. Es profesora de las Universidades Complutense de Madrid y Carlos III de Madrid, donde imparte distintas asignaturas y cursos de postgrado. Trabaja desde 1981 en Radio Nacional de España, en las áreas de documentación y programas, donde ha asumido distintos cargos de responsabilidad. to general as well as specialized queries. All of this occurs within the framework of new digital technologies that affect broadcasting as well as handling and preservation of information.

Keywords: Radiophonic information, Radio programs, Generalist radio programs, Informational radio programs, News radio, Radio theatre, Specialized radio programs, Radiophonic documentation, Recorded music, non-music recordings, Written radiophonic information, Document analysis, Digitization, Digital broadcasting, Radio Nacional de España, Spanish National Radio, Public radio.

Prieto, Laura. "Información y documentación radiofónica: espacios para un interés común. La experiencia de Radio Nacional de España”. En: El profesional de la información, 2007, septiembre-octubre, v. 16, n. 5, pp. 443-449.

DOI: $10.3145 /$ epi.2007.sep.06

\section{Introducción}

DICEN QUE LAS ONDAS TIENEN EL PODER de atraparnos con su magia. Lo tienen para los oyentes, según se desprende de una audiencia que se ha mantenido fiel, no ya cuando era un modo novedoso y casi único de entretenimiento asequible, sino también cuando, con la aparición en su día de la televisión o más recientemente de las nuevas tecnologías que nos conectan al mundo, podía haberse visto relegada en fa- vor de otras formas de acceso a la información y al ocio.

Pero sobre todo, tienen ese poder para los profesionales que cada día hacen la radio. Para ellos, este medio es como para los actores el teatro: un veneno que pone alas a la imaginación y que obliga a explotar cada uno de los recursos que se ponen en juego en el arte de la comunicación. En la radio no existe un texto que se le proporcione al oyente para que pueda interpretar las palabras; tampoco existen imá- genes que la audiencia pueda mirar para descifrar los gestos. En la radio sólo existe la voz y el sonido, y con estos dos sencillos elementos hay que obtener la complicidad del oyente para que interprete la realidad cotidiana, para que imagine esos elementos escritos y visuales que no por intangibles dejan de estar flotando en el aire, viajando por las ondas, o por los cables, o por cualquier medio que hayan inventado o lo hagan en el futuro los científicos, pero siempre viajando. 
"En la radio sólo existe la voz y el sonido, y con estos dos sencillos elementos hay que obtener la complicidad del oyente para que interprete la realidad cotidiana"

Estas particularidades, en las que radica sin duda el secreto de su magia, han venido condicionando el trabajo que se desarrolla en el interior y en el exterior de una emisora. Los profesionales de la radio necesitan sonido y texto escrito para elaborar sus programas, independientemente de su naturaleza. Desde aquellos primerísimos folletines radiofónicos emitidos en Unión Radio en los inicios de los años treinta y nacidos de la mano de un compositor y crítico musical de la generación del 27 llamado Juan-José Mantecón (conocido bajo la firma de Juan del Brezo) y de las primeras retransmisiones de conciertos de música culta desde los propios estudios de la emisora, el camino recorrido ha conocido un trazado evolutivo que, sin embargo, no ha alterado, o lo ha hecho en muy poca medida, sus necesidades intrínsecas.

\section{Pautas de programación en RNE. Programas informativos}

La radio nace con el doble objetivo de informar y entretener, del que se derivan las distintas configuraciones de programas, que podrían dividirse a grandes rasgos en dos tipos: los informativos y los de entretenimiento, de contenido social y cultural.

Los primeros constituyen la columna vertebral de cualquier emisora y en torno a ellos se articula el resto de la programación. La tónica habitual en las emisoras ha sido la de ofrecer tres espacios informativos principales en horarios de mañana, mediodía y tarde-noche, sin perjuicio de intercalar otros espacios breves, coincidiendo con las señales horarias, que han permitido mantener una política de continuidad en la oferta de información de actualidad.

En realidad, éste es uno de los rasgos que han caracterizado a la radio, considerada tradicionalmente como el más ágil de todos los medios. Lo es también hoy, cuando pareciera que el desarrollo de la tecnología televisiva podía arrebatarle ese puesto, ya que las necesidades técnicas y humanas imprescindibles para una emisión televisada aún son considerablemente mayores que las implicadas en la radiofónica. Y en cuanto a la prensa escrita, el salto es todavía mayor en el caso de los diarios impresos, si bien en lo que se refiere a la prensa digital, existe un considerable esfuerzo de aportación de contenidos de valor añadido, como la actualización permanente de la información.

\section{"La radio se considera tradicionalmente el más ágil de todos los medios informativos"}

Para la creación de los espacios informativos se utilizan tres tipos de materiales: el textual, el sonoro no musical y el sonoro musical. Empezando por el último, el peso mayor del material sonoro musical radica en las sintonías que identifican el espacio y en las ráfagas que separan los bloques informativos, también con ese rasgo identificativo. Ocasionalmente, una información que aluda a un espectáculo puede estar ambientada con algunos se- gundos musicales del mismo. Por lo que respecta al material sonoro no musical, éste se nutre de declaraciones, entrevistas y testimonios, tanto de los protagonistas principales de la información como de los secundarios.

Caso distinto es el de la información textual, que no suele tener un uso directo en la elaboración del informativo, con algunas salvedades, como serían, por citar algunos ejemplos, las lecturas (íntegras o parciales) de comunicados, sentencias judiciales, textos legales, manifestaciones políticas, etc., o de teletipos, cuando la urgencia informativa así lo requiere y no haya sido posible la elaboración y/o ampliación de la noticia. Al margen de estos casos concretos, la información textual sirve para apoyar la redacción de una noticia, aportando datos que permitan establecer sus antecedentes y consecuentes, así como el contexto en que se produce.

Este tipo de materiales tienen diferentes vías de entrada, tratamiento y conservación dependiendo de su naturaleza. Siguiendo el mismo orden, una sintonía podrá ser producto del encargo directo a un compositor o de un acuerdo de uso con un compositor sobre alguna obra existente. En ambos casos, está sujeta al pago de los correspondientes derechos de autor y las obras pasan a formar parte de los fondos del centro de documentación, siguiendo las correspondientes pautas de tratamiento documental y conservación. Una tercera vía es recurrir a obras o fragmentos de obras ya exentas del pago de derechos de autor o bien de creación propia de la emisora.

En los años sesenta y primeros setenta, Radio Nacional de Espa$\tilde{n} a(R N E)$ mantuvo una política de encargos a compositores como medio para fomentar la dinamización de nuestros músicos y como parte del cumplimiento de su papel como 
servicio público. Pero ya desde la década de los ochenta se vienen utilizando a tal fin obras exentas, esto es, creadas por autores de cuyo fallecimiento hayan transcurrido más de ochenta años. Estas piezas proceden de grabaciones comerciales y forman parte de los fondos del centro de documentación, que mantiene una política de compras anual sobre la producción discográfica tanto nacional como extranjera.

En lo que afecta a la ambientación musical, el peso en los programas informativos puede considerarse menor frente a la utilización de otro tipo de materiales, y tiene su origen en las grabaciones que se hacen en directo de los espectáculos. Cuando son grabaciones de apenas algunos segundos o unos minutos que no pretenden más que la ilustración de la noticia, no se conservan entre los fondos documentales como piezas aisladas, sino dentro de la referencia global del programa.

Los materiales sonoros no musicales, en la medida en que son entrevistas, declaraciones o testimonios de los protagonistas de la información, proceden con frecuencia del trabajo de campo de los reporteros allá donde se encuentra el foco informativo, aunque también pueden ser fruto de grabaciones realizadas en los propios estudios de las emisoras, ya sea porque acudan los personajes, o bien a través del contacto telefónico. Si las declaraciones se emiten en directo, el material pasa a formar parte tal cual del fondo documental, a menudo incluso desde una doble vía. Esto es, se somete en sí mismo a tratamiento documental el programa donde se han incluido éstas, considerado como referencia única y unívoca y, por otra parte, las propias declaraciones, tratadas también como referencias únicas y unívocas. Esto significa que si por ejemplo se hace una entrevista al presidente del gobierno en el informativo de las ocho de la mañana, en el fondo habrá una referencia que tratará el programa informativo en su conjunto, y otra que tratará la entrevista individualmente. Esto facilitará que si en algún otro momento se quiere utilizar la entrevista, el acceso sea inmediato y con absoluta pertinencia.

\section{"Si las declaraciones se emiten en directo, el material pasa a formar parte tal cual del fondo documental, a menudo incluso desde una doble vía"}

En cuanto al material que procede del trabajo de campo de los reporteros, puede suceder que se emita en directo o no. Si se emite en vivo se siguen las pautas antes mencionadas, pero ¿qué sucede cuando no es así? En este caso, el reportero llega a la emisora con un material grabado que servirá para acompañar la redacción de piezas informativas o reportajes, pero aquí dicho material no se suele utilizar en su totalidad, sino que se hace uso de algún fragmento. Sin embargo, esto no significa que el resto se deseche, puesto que se considera valioso para futuros usos. Este material de campo, conocido en el argot profesional como "brutos", pasa al fondo documental y constituye una referencia única, con independencia de que el programa informativo en el que haya aparecido el fragmento o fragmentos se analice por su lado.

Esta doble vía no debe considerarse un desperdicio de los recursos técnicos y humanos. Pese a que el análisis de un programa informativo lleve un minutado que permita ubicar exactamente en qué punto se encuentra cada información concreta, el trabajo con soportes analógicos ralentizaba bastante el acceso y la posterior edición del rango que se quisiera reutilizar.
Es cierto que los soportes digitales facilitan mucho esta tarea, pero aun así, se necesitarían sistemas con los que se pudiera apuntar automáticamente hacia un minuto concreto de la programación y a partir de ahí extraer el fragmento deseado para su edición. En este aspecto, aunque se han conseguido ya avances muy interesantes, no se tiene todavía el desarrollo suficiente para garantizar tanto la fiabilidad como la rapidez necesarias en un medio de comunicación. Al menos no lo suficiente como para plantearse en este momento un cambio en las pautas de trabajo, aunque sí lo sea para su consideración en un futuro cercano. Por otra parte, el tratamiento de determinados materiales autónomos se debe a su valor, no ya desde el punto de vista informativo y documental, sino también desde una perspectiva histórica, algo que no debe estar ausente en un organismo público como $R N E$.

Finalmente, los materiales textuales tienen una procedencia que podemos calificar de diversa. De un lado, la recepción diaria de teletipos de agencias como Efe, France Press, Reuters o Europa Press entre otras, proporcionan el pulso del interés informativo mundial, a la par que ofrecen los datos sustanciales de las noticias. Una representación de estos teletipos y agencias se conservan en la base de datos, que tiene unas entradas anuales de aproximadamente medio millón de documentos. De otro, el trabajo de campo, en particular en lo referente a instituciones (ya sean públicas o privadas) de carácter político, económico, social y cultural, es una valiosa fuente para recabar información de actualidad.

Junto a éstas, el propio centro de documentación tiene asimismo una trascendencia de primer orden como suministrador de información. Cada día recepciona todos los periódicos nacionales y muchos otros a nivel regional e internacional. Se reciben también revistas de información 
general de carácter semanal o quincenal y un amplio número, cercano a las cuatrocientas cabeceras, de revistas especializadas en las temáticas que son susceptibles de interesar a un medio de comunicación. Todo este material es sometido a procesos de selección, análisis y digitalización para incorporarse a la base de datos. A esto hay que añadir un fondo bibliográfico integrado por obras de referencia, monografías y literatura gris, así como un fondo histórico cuya información se remonta a principios del siglo $\mathrm{XX}$. Este conjunto de materiales supone a día de hoy alrededor de unos tres millones de documentos accesibles on line, tanto en lo que afecta a las referencias como a un porcentaje que ronda el setenta por ciento de los documentos originales.

\section{Magazines}

Otro tipo de programas con un peso importante en el conjunto de la programación son los llamados magazines. Amalgama de informaciones de contenido político, económico, social y cultural, éstos se mezclan con el entretenimiento $\mathrm{y}$, en los últimos años, con la fórmula de las tertulias. Se emiten en horario de mañana, tarde y noche, siendo los primeros los que suelen ocupar el horario más amplio, que viene a oscilar entre tres y cinco horas. Los materiales utilizados coinciden en buena parte con los especificados para los programas informativos (sintonías, textos, material sonoro no musical) aunque aquí las noticias se desarrollan con mayor profundidad, incluyendo los comentarios personales de los participantes en las tertulias, que pueden ser tanto periodistas como personajes relevantes de la actualidad o de campos concretos del saber. Tienden a dividirse en secciones diferenciadas y pueden dedicar alguna de ellas a temas intemporales, esto es, que no están necesariamente vinculados a la actualidad más inmediata.

\section{"Todas y cada una de las grabaciones que anualmente realiza $R N E$ tanto en el campo de la música culta como en el de la ligera, se tratan y conservan en el centro de documentación"}

El material sonoro musical adquiere aquí un protagonismo mayor que en los programas informativos, pudiendo jugar un papel de ambientación o ilustrativo de noticias concretas. El primero agiliza y apoya los contenidos, mientras el segundo constituye en sí mismo una parte de la información. El centro de documentación se encarga de proveer estos materiales de acuerdo con un sistema de adquisición de la producción discográfica comercial tanto nacional como internacional, que pasa a formar parte de los fondos tras su oportuno tratamiento documental. Aunque no se encuentre entre sus obligaciones, la fonoteca de $R N E$ se ha convertido de hecho en un referente en cuanto al tratamiento y conservación de esta producción comercial y, en esta medida, proyecta sobre sus fondos un interés histórico añadido.

También se encarga de proveerlos a través de las grabaciones que realiza en auditorios y salas de concierto, en este último caso, sujetas a unas determinadas condiciones contractuales y al pago de derechos de propiedad intelectual. Los contratos no implican obligatoriamente una contraprestación económica, sino que pueden obedecer a acuerdos de colaboración recíproca de muy distinta índole. En cualquier caso, todas y cada una de las grabaciones que anualmente realiza $R N E$ tanto en el campo de la música culta como en el de la ligera, se tratan y conservan en el centro de documentación, constituyendo uno de los patrimonios más importantes que posee, en la medida en que son testigos y pulso de nuestro patrimonio y actividades culturales. En esa misma medida, su valor histórico es incalculable, toda vez que son documentos únicos. Cabe apuntar aquí que $R N E$ es la propietaria de las grabaciones, que no de los derechos de emisión (sujetos a las condiciones del contrato) ni de los derechos de autor.

\section{Programas/emisoras especializados}

Este tipo de programas son hoy comunes a todas las emisoras llamadas generalistas. Radio Nacional, por su parte, incluye en su conjunto de emisoras otras de carácter especializado, condicionadas por unas necesidades propias, las cuales son extrapolables en gran medida a las de otras emisoras especializadas, así como a determinados programas especializados de las emisoras generalistas.

\section{"El tratamiento documental en Radio Clásica implica la colaboración de un asesor musical y la consulta permanente a numerosas obras especializadas"}

Así por ejemplo, el panorama nacional presenta un buen número de emisoras dedicadas a la denominada música ligera. El mayor porcentaje de éstas se dedica a la música comercial, mientras algunas, como es el caso de Radio 3 de Radio Nacional, dedican parte de sus recursos a la grabación de acontecimientos musicales concretos, ya sea para su emisión en directo o en diferido. Como hemos comentado, 
este tipo de grabaciones se consideran de gran valor no sólo informativo, sino también documental e histórico. Otro ejemplo es el de Radio Clásica. Si Radio 3 incluye en su parrilla programas no estrictamente musicales, esta última es una emisora diseñada íntegramente en torno a la música culta, que emite exclusivamente espacios musicales en los que se alterna la producción comercial con las grabaciones propias.

En lo referente a Radio 3, es el centro de documentación quien se adelanta a sus necesidades y pone a su disposición el material obtenido mediante compra. En el caso de Radio Clásica, es el servicio de grabaciones quien custodia el material hasta su emisión para pasar posteriormente al centro de documentación. Cuando la emisión ha sido en directo, la incorporación es muy rápida, no así cuando es en diferido, que puede demorarse varios días. Radio Clásica, por otra parte, tiene la condición de ser la única emisora española dedicada a tal fin. Hace unos años hubo un intento por parte de una emisora privada de dedicar su parrilla a la música culta, pero no llegó a buen puerto. No cabe duda de que esto hace de Radio Clásica un hecho singular, por lo que su nivel de especialización es muy elevado. Por ello, el tratamiento documental en este campo responde también a esa especialización, convirtiéndose en un proceso exhaustivo que implica la colaboración de un asesor musical y una consulta permanente a numerosas obras como catálogos de compositores, enciclopedias, monografías y un largo etcétera.

Otro tipo de programas especializados pueden obedecer a los más variados ámbitos de la actualidad. Son frecuentes en todas las emisoras los espacios deportivos, que dedican una parte de su quehacer a las retransmisiones en directo, muy en particular de partidos de fútbol. Estas emisiones se conservan en el fondo bajo el criterio de referencia por programa. Sin embargo, cuando el contenido incluye declaraciones o entrevistas, siguen las pautas mencionadas anteriormente. Estas últimas son comunes a otros muchos espacios dedicados a temáticas como cultura, economía, medioambiente, salud y otros de proyección social, sin perder de vista lo apuntado respecto a sintonías o ambientación musical.

\section{Programas dramáticos}

Un último capítulo que merece la pena resaltar por su singularidad es el de los programas dramáticos. Aunque es una variante que ha caído en desuso, hasta los años noventa fue una seña de identidad en $R N E$, contando incluso con su propio cuadro de actores en plantilla, al que con frecuencia se incorporaban primeras figuras de la interpretación, contratados para papeles concretos. Así, el centro de documentación conserva en su fondo de dramáticos las voces de numerosos actores y actrices de nuestra escena. De nuevo debemos hablar, como en el caso de las grabaciones musicales, de su interés histórico y del carácter único de estos fondos.

Los materiales para construir un espacio dramático, al margen obviamente de contar con una sintonía propia, son el texto y materiales sonoros tanto musicales como no musicales. Aquí el texto no ejerce un papel de apoyo sino que es parte del contenido mismo, en tanto que los actores lo que realizan es una lectura dramatizada, ya sea de textos del repertorio clásico, o nuevas creaciones encargadas al efecto (léase folletines, novelas radiofónicas, cuentos, etc.). Por el contrario, la música sí es utilizada en un papel de ambientación que pretende resaltar el significado de los textos. En cuanto al material sonoro no musical, y fuera de la consideración que como tal puedan tener las voces de los actores, entra en juego un nuevo elemento que, bajo la denominación genérica de "efectos", aglutina todo tipo de ruidos y sonidos medioambientales que se ponen al servicio del texto. Éstos pueden ser desde el relinchar de un caballo, ruidos de pasos, objetos que caen, cristales que se rompen, puertas que se cierran o un molino de agua girando, hasta el sonido de la lluvia o los truenos. De lo más cotidiano a lo más insólito, los efectos ponen en situación al oyente, supliendo la carencia de lo visual. Junto a algunas grabaciones realizadas en los estudios, el grueso de los fondos de efectos que se encuentran en el centro de documentación proviene de la compra de producciones comerciales que ocupan su propio hueco en el mercado.

\section{Cuñas publicitarias}

Finalmente, no podemos dejar de hablar de esta categoría, considerada también como material sonoro no musical y del que se nutren las emisoras privadas, ocupando un porcentaje determinado de su parrilla. Incrustadas en los programas o utilizadas como espacios con entidad independiente entre unos y otros, su procedencia puede venir del mundo privado, si se trata de publicidad de productos; público, si estamos ante campañas de comunicación o de ambos si son ofertas o información sobre servicios. En función de ello, su propiedad puede ser pública o privada y su contenido se compone de texto, voces, música y efectos, aunque no necesariamente han de estar presentes estos cuatro elementos. Por lo que afecta a $R N E$, aun no teniendo publicidad, sí ha adquirido y conservado grabaciones comerciales de cuñas, en particular en lo que se refiere a las décadas de los cuarenta, cincuenta y sesenta.

\section{Tratamiento documental de los materiales}

Como puede observarse el centro de documentación de $R N E$, como por otra parte es previsible, 
realiza tareas comunes a los de cualquier otro medio de comunicación, poniéndose al servicio de las necesidades de la emisora. Al confluir en ella tanto los aspectos generalistas como los especializados, el tratamiento documental se ha diseñado tanto para dar respuesta a las consultas sobre datos puntuales, como a aquellas que profundizan ampliamente en temas concretos. Y se ha preparado para cumplir con dos reglas básicas en la documentación, esto es, rapidez y pertinencia, que se antojan aún más imprescindibles cuando de un medio de comunicación se trata donde, con suma frecuencia, se impone la urgencia informativa.

\section{"En un impulso que aunó esfuerzos, se procedió a reconvertir, y en algunos casos a restaurar, el sonido analógico de sus casi novecientos mil soportes, en digital"}

En todo ello ha aportado un salto cualitativo la tecnología digital, que se lleva ya aplicando desde hace doce años, con la incorporación de las imágenes digitalizadas de los documentos originales en el departamento de documentación escrita, pionera en este sentido en el desarrollo y la implantación de un sistema digital multimedia en el ámbito de los grandes gestores documentales. La tecnología digital no sólo tiene que ver con un modo de conservar y utilizar los documentos con mayor seguridad, estabilidad, calidad y ahorro de espacio, sino que implica también un cambio en los procedimientos de trabajo, incluido el análisis de contenidos. Ha aportado además algo que preocupaba a los responsables, y es la posibilidad de que todos los profesionales, desde cualquier emisora territorial, incluso desde las corresponsalías, puedan tener un acceso inmediato a los fondos documentales a través de la intranet corporativa.

Si bien, como se ha dicho, la documentación escrita fue la primera en lanzarse al mundo digital, el hecho que quizás ha tenido una mayor proyección mediática y un mayor impacto dentro de la propia empresa ha sido la completa digitalización de todos los fondos sonoros de la emisora. En un impulso que aunó los esfuerzos de las áreas técnica, informática y documental, se procedió a reconvertir, y en algunos casos a restaurar, el sonido analógico de sus casi novecientos mil soportes, en digital, con el resultado de alrededor de un millón y medio de registros (unas doscientas mil horas de sonido) disponibles on line.

La conversión retrospectiva fue de gran magnitud. Se tardaron cuatro años en poder completar el proceso y se necesitó la intervención de numerosos recursos técnicos y humanos. Se atendieron asimismo los requisitos del sistema de emisión digital implantado en $R N E$ poco antes del comienzo de la digitalización de los fondos sonoros. Ambos sistemas están integrados satisfactoriamente de manera que desde el sistema de emisión se accede a los fondos, mientras que el sistema documental permite capturar la emisión para su posterior análisis.

La tecnología digital ha traído consigo cambios importantes en cuanto al conjunto del tratamiento documental, siendo lo más significativo el acceso al documento original, probablemente una de las aplicaciones más valoradas por nuestros usuarios. Pero, más allá de lo que se ve, la labor del centro de documentación se ha visto sacudida por una revolución en la que se han producido considerables ahorros de tiempo en algunos procesos, como la generación automática de regis- tros documentales o la implementación del texto completo en los documentos textuales, que aumenta enormemente la potencialidad de búsqueda. Unido a las tradicionales catalogación e indización, da como resultado la máxima precisión.

\section{"El documentalista ha de jugar el doble papel de dar servicio con los mejores medios a su alcance, y de demandar de la industria nuevos medios para mejorar ese servicio"}

En cuanto a los formularios de búsqueda, la posibilidad de invertir los tesauros y otros lenguajes documentales a índices textuales, permite que los usuarios puedan moverse entre los fondos de una forma tan natural e intuitiva como lo hacen a través de los conocidos buscadores de internet. Sin embargo, otros procesos, como es el caso de la digitalización y asociación de los documentos originales, añaden no sólo el factor tiempo, sino el conocimiento de numerosas herramientas informáticas, abriendo aún más las competencias profesionales de los documentalistas. En todo caso son elementos que se diseñan no pensando en el ahorro para los documentalistas, sino para los usuarios, y aquí es donde se puede apreciar en toda su magnitud.

La renovación tecnológica tiene todavía muchas puertas por abrir, como la mejora en el reconocimiento de caracteres o el desarrollo en el de voz, aún muy poco evolucionadas, o el de las plantillas vocales e instrumentales de los documentos musicales, que pertenecen al futuro, por no hablar de otros servicios, como la implementación de informaciones vinculadas o relacionadas con los documentos. 
Sea como fuere, el documentalista ha de dar servicio con los mejores medios a su alcance, y demandar de la industria nuevos medios para mejorarlo, todo ello con un mismo objetivo final: la satisfacción del usuario. Sólo con la consecución decidida de ese doble papel, los profesionales de la documentación podremos contribuir a que la nuestra sea una plena sociedad del conocimiento.

\section{Bibliografía}

Balsebre, Armand. El lenguaje radiofónico. Madrid: Cátedra, 1994. Isbn 84-376-1236-5.

Bonet, Montse; Fernández-Quijada, David "El reto de la digitalización del archivo sonoro en los servicios públicos de radiodifusión. El caso de Catalunya Ràdio". En: El profesional de la información, 2006, v. 15, n. 5, sept.-oct., pp. 390-396.
Díaz, Lorenzo. La radio en España 1923-1993. Madrid: Alianza Editorial, 1995. Isbn 84-206 9652-8.

Díaz-Mancisidor, Alberto. Radio y televisión Introducción a las nuevas tecnologías. Madrid: Paraninfo, 1991. Isbn 84-283-1817-4.

Díaz-Mancisidor, Alberto; Urrutia, Víctor. $L a$ nueva radio. Bilbao: Universidad del País Vasco, 1986. Isbn 84-7585-053-7.

Ezcurra, Luis. Historia de la radiodifusión española. Los primeros años. Madrid: Editora Nacional, 1974. Isbn 84-276-1201-X.

Fernández-Sande, Manuel. Los orígenes de la radio en España. Madrid: Fragua Ediciones, 2005. Isbn 84-7074-182-9.

González-Conde, María-Julia. Comunicación radiofónica. De la radio a la universidad. Madrid: Universitas, 2001. Isbn 84-7991-120-4.

Miranda-Regojo, Fátima. La fonoteca. Salamanca; Madrid: Fundación Germán Sánchez Ruipérez: Pirámide, 1990. Isbn 84-368-0524 0.

Muñoz, José-Javier; Gil, César. La radio. Teo- ría y práctica. Madrid: Instituto Oficial de Radio y Televisión, 1988. Isbn 84-86984-10-6.

Newman, John F. Periodismo radiofónico México: Lamusa, 1991. Isbn 9681840682.

Ortiz, Miguel-Ángel; Cuesta, Juan. La radio digital. Nuevos perfiles profesionales. Madrid: Instituto Oficial de Radio y Televisión, 2004. Isbn 84-88788-51-1.

Pedrero-Esteban, Luis-Miguel. La radio musical en España. Historia y análisis. Madrid: RTVE, 2000. Isbn 84-88788-42-8.

Prieto, Laura; Montero, Pilar. "El documentalista ante la sociedad de la información: experiencia en aplicaciones multimedia en Radio Nacional de España como respuesta a la demanda estructurada de documentación". En: III Jornadas andaluzas de documentación, 2003, pp. 147 156. Isbn 84-931167-1-8.

Laura Prieto, Universidad Complutense de Madrid. Radio Nacional de España

lauraprieto53@hotmail.com

\section{CJALS|2007}

en la Sociedad de la Información
14-16 de noviembre

Universidad Politécnica de Valencia

\section{"Información Digital: Nuevas perspectivas en la sociedad del Conocimiento"}

\section{CALSI 2007}

Es el punto de encuentro de los profesionales de la gestión de la información y de los sectores clave para el desarrollo de la Sociedad de la Información y del Conocimiento. En este congreso se analizan los cambios tecnológicos y su aplicación en los nuevos canales de información donde el tratamiento la información es fundamental.

\section{BLOQUES TEMÁTICOS}

La e-administración.

Gestores documentales para la e- administración.

Web 2.0 aplicado a servicios de información.

Tecnologias emergentes, experiencias y tendencias Futuras.

Revistas científicas digitales.

Situación actual y perspectivas de futuro

Acceso abierto a la ciencia.

Las redes de conocimiento en el Espacio Europeo de Investigación.

\section{DESTINATARIOS}

Documentalistas, bibliotecarios, archiveros, abogados, periodistas, ingenieros informáticos y de telecomunicaciones, economistas, responsables de marketing, graduados sociales, publicistas, webmaster y, en general, a los responsables y gestores de la información y la documentación.

\section{PONENTES}

Profesionales que trabajan en el ámbito de las nuevas tecnologías e Internet que ofrecerán desde un punto de vista cualificado propuestas y perspectivas para el desarrollo de la sociedad de la información.

\section{INSCRÍBETE YA!}

www.calsi.org

Camino de Vera s/n, 46022 Valencia

Telefono: 963877000 (Ext. 88924)

Mail: info@calsi.org

\section{Organiza}

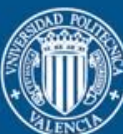

UNIVERSIDAD

POLITECNICA

DE VALENCIA

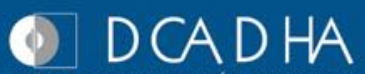
DPTO. DE COMUNICACIÓN AUDIOVISUAL
DOCUMENTACION E HISTORIA DEL ARTE
Financia

INSTITUTO

DE DISENNO Y FABRICACIÓN
2: CENERALITAT IALENCIANA 